\title{
A Study of Phyto-Pharmaceutical Formulation for Smooth Capsule Filling
}

\author{
Syed Junaid Rehan ${ }^{1}$, Kamran Alam ${ }^{2}$ Hina Rehman ${ }^{2}$ Rabia Bashir ${ }^{2}$, \\ Zeeshan Ahmed ${ }^{2}$ \\ ${ }^{I}$ (Research \& Development Department, Herbion Pakistan Pvt. Ltd. Pakistan) \\ ${ }^{2}$ (PIQC-Institute of Quality, Hamdard University, Pakistan)
}

\begin{abstract}
A good flow ability of granules or powder ensures efficient mixing, uniform dose as well as weight distribution in solid dosage form. Reformulation of product done for use of excipients that would aid in manufacturing of large, uniform, spherical \& dense granules then redesign of manufacturing techniques. Series of trials conducted to select most appropriate excipients and their optimum ratios, and techniques, subsequently evaluating and identifying parameters obtained from angle of repose, carr's index \& Hausner Ratio.

The project is designed to facilitate, improve the process of granules or powder filling in capsules (flow ability), reduction of weight variation of capsules and also cut down the number of workers utilization for the capsule manufacturing process, which is based on herbal formulation that is phytopharmaceutical health care products, in which the Active is derived/extracted from the herbs and that is in large quantities and semisolid in nature, as compared to the Allopathic medicines where API's are in limited quantity and are mostly in the form of powder which can be easily mixed with other excipients and diluents to achieve uniform capsule filling.
\end{abstract}

Keywords: Angle of Repose, Bulk Density, Flowability, Tapped Density, Thick Extract

\section{INTRODUCTION}

In Herbion, have been utilizing Manual Capsule Filling System which fills one batch of capsule with 15 operators. But with increased demand and new technology in hand we can not only speed up process but also save time, labor, energy and money of the company as well, therefore we decided to go with Automatic Capsule Filling Machine.

But for Automatic Machine we needed to redesign or reformulate the product formulation (granules or powder) by using high quality and more compatible Raw Materials which must provide proper uniform shape, size and density in order to have better flow which ultimately ensure efficient mixing, uniform dose as well as weight distribution in solid dosage form.

\section{RESEARCH DESIGN}

Inconsistency in uniform capsule filling may result from

1. Large differences in the granule particle size (from coarse to fine)

2. Agglomeration of the granules

3. Stickiness of particles with dosing hopper

4. Poor flow characteristics

5. Electrostatic charge that retards the transfer from the dosing chamber into the capsule body.

So strategy is to identify, a stable and optimized formula and manufacturing process for future product batches that will result in granules, free from aforementioned qualities which will facilitate encapsulation.

Therefore, for this purpose study of in-active materials, their property for alternates were carried out and improvement made in the formulation \& simultaneously the manufacturing process and techniques are modified to achieve the desired results.

\section{Regular Formulation with Manufacturing}

\section{Procedures}

Preparation of wet mass:

Take Thick Extract, Talcum Powder, Di-Calcium phosphate, Citric acid and Potassium sorbate in Mixer as per formulation and mix for 5 to 10 minutes.

Then add product extract in it and mix for 15 to 20 minutes to get the wet mass Drying:

Take the wet mass from STEP 1 and divide in to small pieces. Then spread on S.S. trays. Dry the wet mass in tray drier at $90 \mathrm{OC}$ for 8 to 12 hours. 
Grinding and sieving:

After drying wet mass, start grinding in to dust catcher grinder with the mesh No. 10.

Repeat the process using mesh No. 24.

Final sieving:

Sieve the ground powder through mesh \# 40 to get the fine powder.

Collect the fine powder in a separate container.

Check the moisture content of the powder, which should NMT $2 \%$.

Note Total quantity of powder collected for encapsulation $(\mathrm{kg}$.

Preparation of Wet Mass:

\section{New Formulation With Manufacturing}

Take Micro Crystalline Cellulose, Lactose Anhydrous as per formulation in Mixer for 5 to 10 minutes.

Then add product extract in it and mix for 15 to 20 minutes to get the wet mass

Sieving:

Sieve the wet mass from through Mesh No 14.

Drying:

Take the wet sieved mass and spread on S.S. trays. Dry the wet mass in tray drier at $900 \mathrm{C}$ for 8 to 12 hours

Grinding and sieving:

After drying, start grinding in to dust catcher grinder with the Mesh No. 40.

Addition of magnesium stearate after passed from Mesh No 60

Final sieving:

Sieve the ground powder through mesh \# 40 to get the fine powder.

Collect the fine powder in a separate container.

Check the moisture content of the powder, which should NMT $2 \%$.

Note Total quantity of powder collected for encapsulation $(\mathrm{kg}$.

\section{Interpretations of the Results}

Comparative Data Analysis

The following part contains data of different parameters studied to observe the changes in Existing and New Capsule Formulation.

\section{Particle Shape and Particle Size}

It is well known that particle size influences flow ability. For example particles of different sizes, tend to be more cohesive and therefore less free-flowing, whereas larger, spherical and denser particles tend to be free flowing.

So, we reformulated our capsules in such a way that final granules are denser, spherical and of uniform size and shape to facilitate uniform and well controlled flow.

Figure 1 shows New and Existing Bonjigar, Intellan and Verona Plus Capsule Formulations demonstrating the difference in particles' morphology. It can easily be seen that new formulations have sharp and compact granules whereas granules of old formulations lack uniformity in terms of shape and size.

Figure 1: showing the Micrographs of New and Existing Capsule Formulation

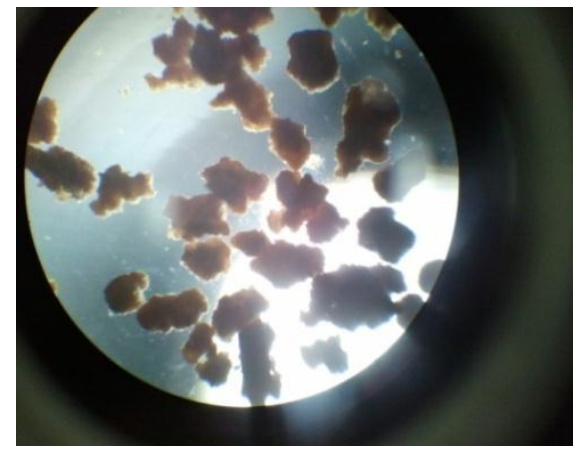

Bonjigar Capsule New Formulation

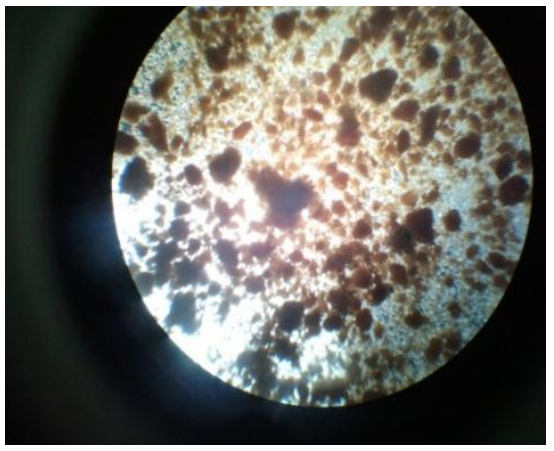

Bonjigar Capsule Existing Formulation 


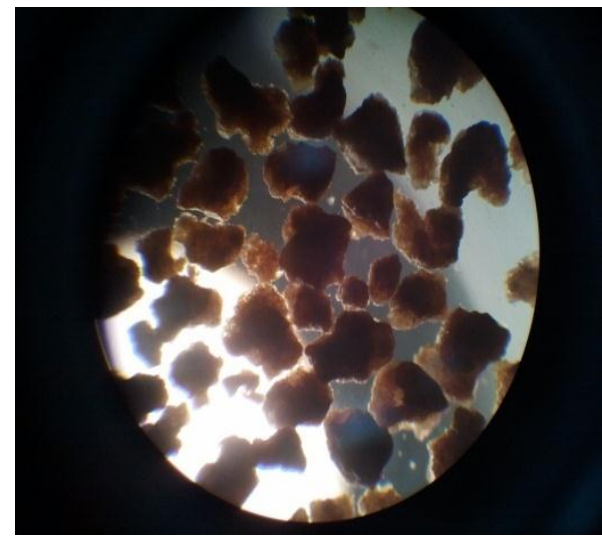

Intellan Capsule New Formulation

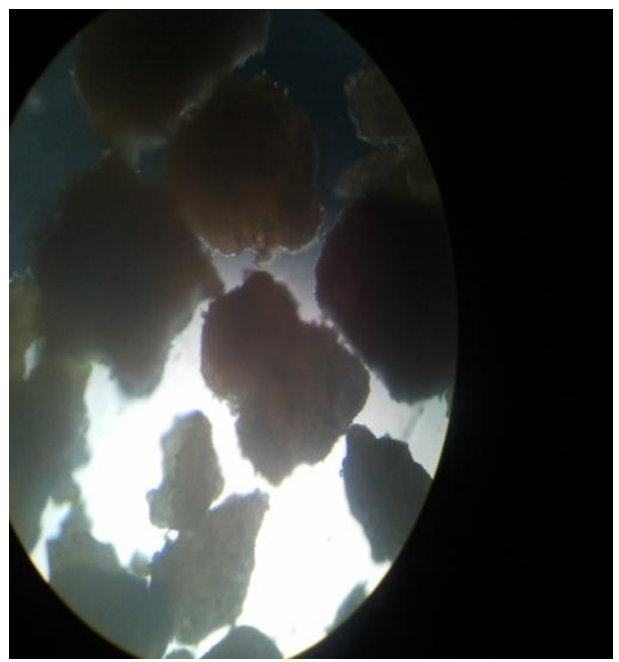

Entoban Capsule New Formulation

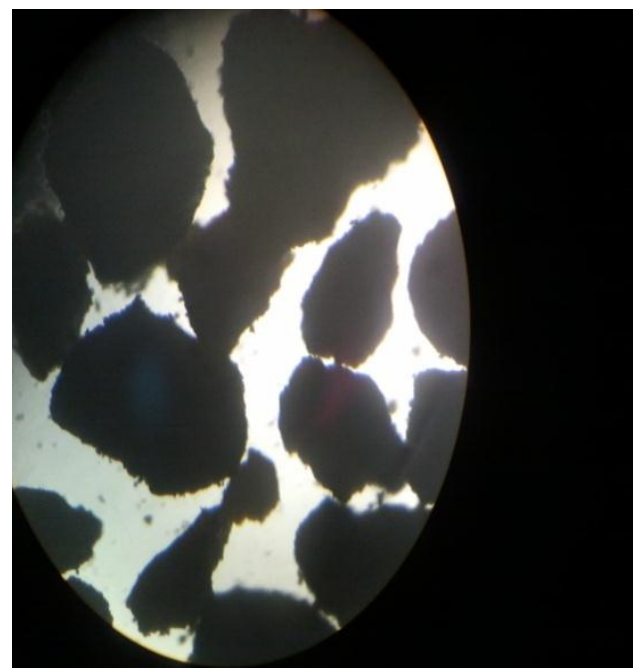

Verona Capsule New Formulation

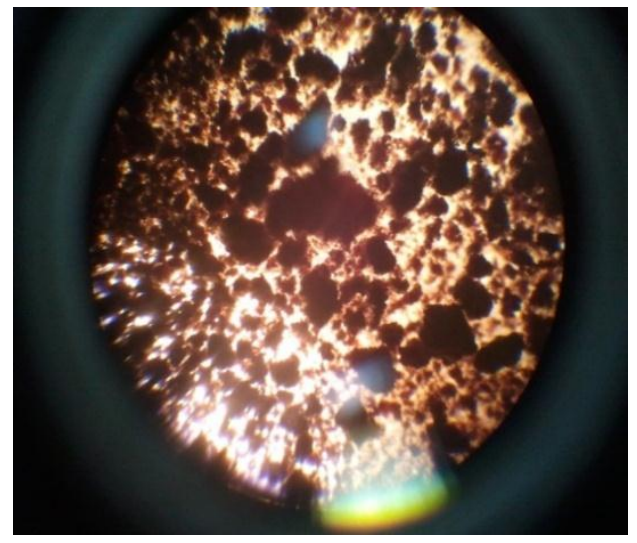

Intellan Capsule Existing Formulation

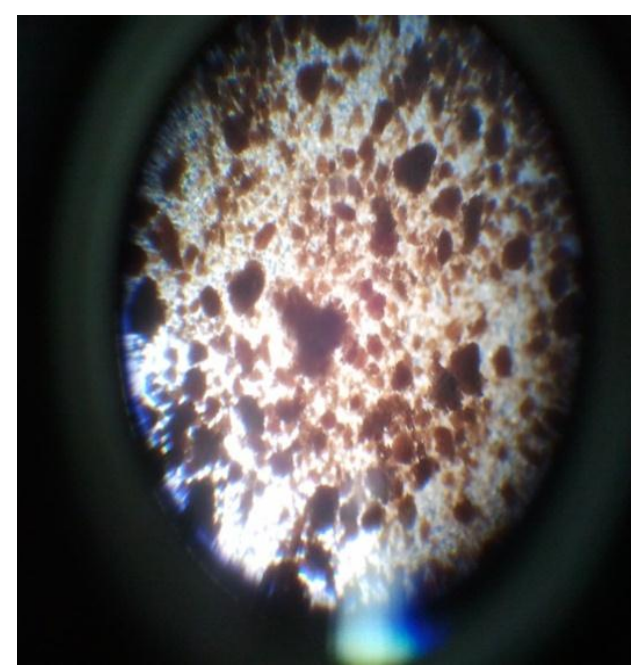

Entoban Capsule Old Formulation

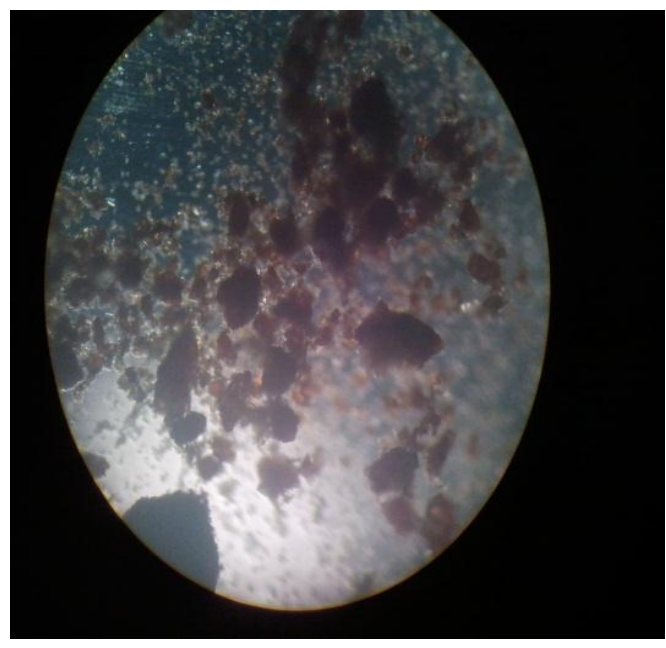

Verona Capsule Existing Formulation 


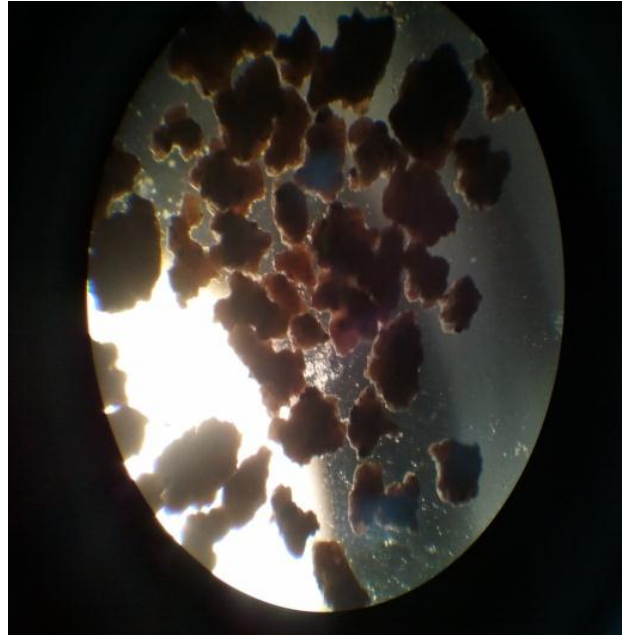

Verona Plus Capsule New Formulation

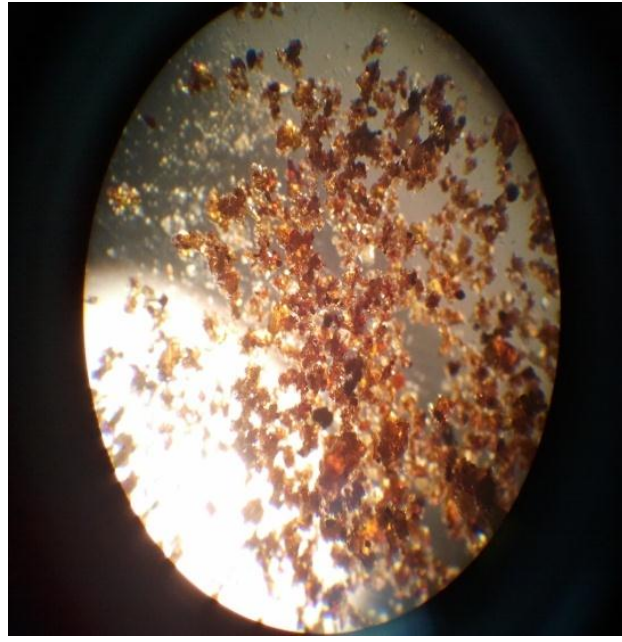

Verona Plus capsule Existing Formulation

\section{Flow Properties}

The flow rate measures the ability to be transferred. It is the property of the powder or granules by which it flows readily and fills the mould cavity. Therefore during the filling process the capsule shell must be filled rapidly with powder to achieve high rate of production and economy.

Hence the flow rate is influenced by

1. The shape of the particles

2. Coefficient of friction and

3. Size of the particle.

4. Density of particle.

Angle of Repose, Hausner Ratio and Carr's Index all are measure of the flow properties of powders.

\section{Angle Of Repose:}

Table 1: Flow properties and corresponding Angle of Repose

\begin{tabular}{|c|c|}
\hline FLOW CHARACTER & ANGLE OF REPOSE \\
\hline \hline Excellent & $25-30$ \\
\hline Good & $31-35$ \\
\hline Fair - Aid not needed & $36-40$ \\
\hline Passable - may hang-up & $41-45$ \\
\hline Poor - must agitate, vibrate & $46-55$ \\
\hline Very Poor & $56-65$ \\
\hline Very Very Poor & $>66$ \\
\hline
\end{tabular}

\section{Carr's Index \& Hausner Ratio:}

Table 2: Scale of Flowability

\begin{tabular}{|c|c|c|}
\hline CARR'S INDEX & FLOW CHARACTER & HAUSNER RATIO \\
\hline \hline 10 & Excellent & $1.00-1.11$ \\
\hline $11-15$ & Good & $1.12-1.18$ \\
\hline $16-20$ & Fair & $1.19-1.25$ \\
\hline $21-25$ & Passable & $1.26-1.34$ \\
\hline $26-31$ & Poor & $135-1.45$ \\
\hline $32-37$ & Very Poor & $1.46-1.59$ \\
\hline$>38$ & Very Very Poor & $>1.60$ \\
\hline
\end{tabular}

Data measured and determined for a range of capsule products are shown in Table3. It can be seen from the Hausner ratio and the Carr's index that the granules of new formulation are free flowing compared to existing formulation. 
A Study of Phyto-Pharmaceutical Formulation for Smooth Capsule Filling

Table 3: showing correlation between Flow Index of new and existing capsule formulations

\begin{tabular}{|c|c|c|c|c|c|c|}
\hline S.no & Type & Product & $\begin{array}{c}\text { Batch } \\
\text { number }\end{array}$ & $\begin{array}{c}\text { Hausner } \\
\text { ratio }\end{array}$ & $\begin{array}{l}\text { Carr's } \\
\text { index }\end{array}$ & $\begin{array}{c}\text { Angle of } \\
\text { repose }\end{array}$ \\
\hline 1. & \multirow{5}{*}{$\begin{array}{l}\text { New } \\
\text { Formulation }\end{array}$} & $\begin{array}{l}\text { Bonjigar } \\
\text { Capsule }\end{array}$ & 163.E.12 & 1.043 & 4.137 & 28.87 \\
\hline 2. & & $\begin{array}{l}\text { Intellan } \\
\text { Capsule }\end{array}$ & Trial & 1.021 & 2.111 & 34.06 \\
\hline 3. & & $\begin{array}{l}\text { Entoban } \\
\text { Capsule }\end{array}$ & 215.F.12 & 1.011 & 5.10 & 29.65 \\
\hline 4. & & $\begin{array}{l}\text { Verona } \\
\text { Capsule }\end{array}$ & 216.F.12 & 1.032 & 4.12 & 29.66 \\
\hline 5. & & $\begin{array}{l}\text { Verona Plus } \\
\text { Capsule }\end{array}$ & 155.E.12 & 1.064 & 6.09 & 31.79 \\
\hline 6. & \multirow{5}{*}{$\begin{array}{l}\text { Existing } \\
\text { Formulation }\end{array}$} & $\begin{array}{l}\text { Bonjigar } \\
\text { Capsule }\end{array}$ & 1612023 & 1.189 & 15.93 & 33.11 \\
\hline 7. & & $\begin{array}{l}\text { Intellan } \\
\text { Capsule }\end{array}$ & 2512012 & 1.163 & 14.04 & 38.28 \\
\hline 8. & & $\begin{array}{l}\text { Entoban } \\
\text { Capsule }\end{array}$ & 1912008 & 1.135 & 13.21 & 39.21 \\
\hline 9. & & $\begin{array}{l}\text { Verona } \\
\text { Capsule }\end{array}$ & 3112043 & 1.152 & 14.01 & 36.41 \\
\hline 10. & & $\begin{array}{l}\text { Verona Plus } \\
\text { Capsule }\end{array}$ & 3412001 & 1.161 & 15.86 & 40.12 \\
\hline
\end{tabular}

Color Key:

\begin{tabular}{|c|}
\hline Excellent \\
\hline Good \\
\hline Fair \\
\hline
\end{tabular}

\begin{tabular}{|c|}
\hline Passable \\
\hline Poor \\
\hline
\end{tabular}

\section{Very Poor}

Very Very Poor

\section{Graphical Representation}

Angle of Repose showing flow ability comparison between new and old capsule formulation

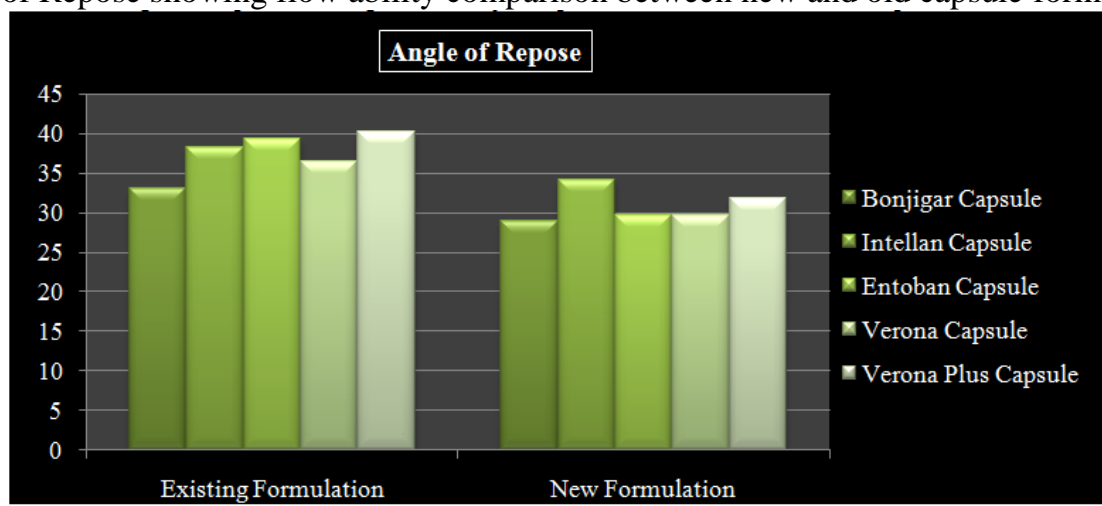

A bar graph showing comparison of Carr's index

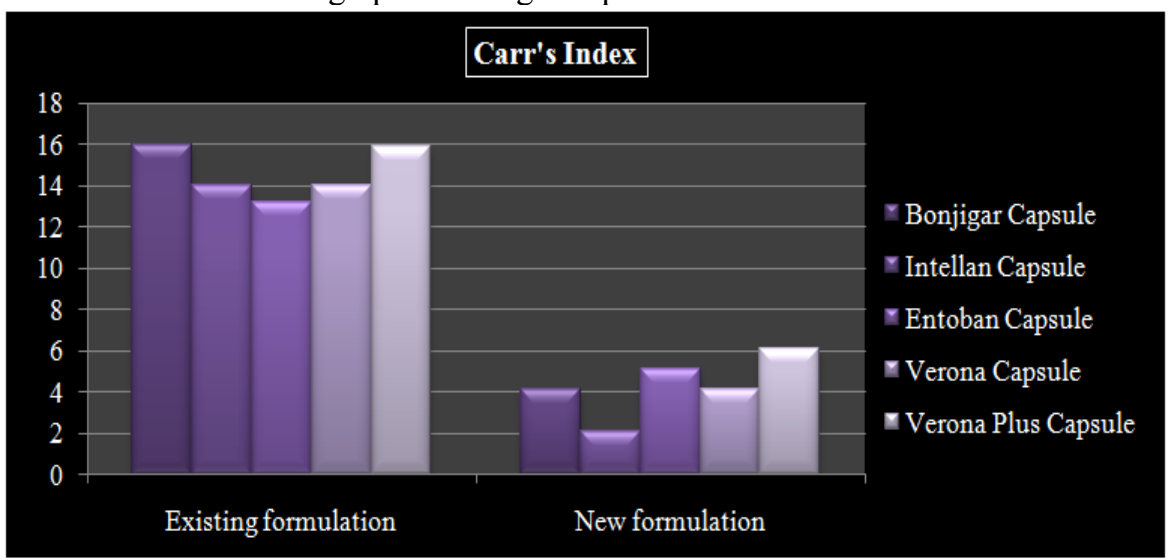


A graph showing comparison of Flowability through Hausner ratio

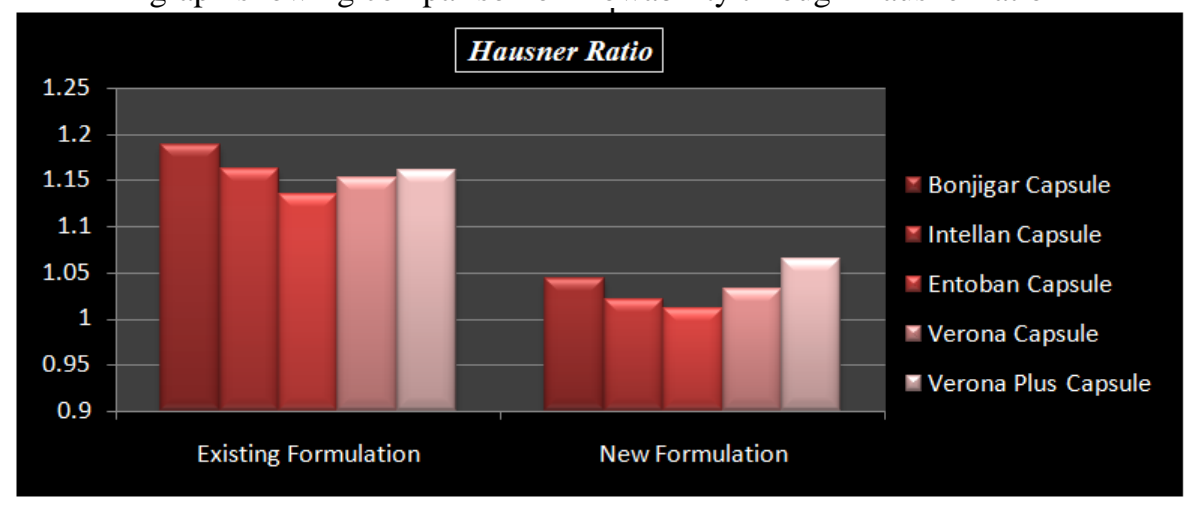

\section{Summary}

The project is designed to facilitate, improve the process of granules or powder filling in capsules (flow ability), reduction of weight variation of capsules and also cut down the number of workers utilization for the capsule manufacturing process in production department, which is based on herbal formulation that is phyto pharmaceutical health care products, in which the Active is derived/extracted from the herbs and that is in large quantities and semisolid in nature, as compared to the Allopathic medicines where API's are in limited quantity and are mostly in the form of powder which can be easily mixed with other excipients and diluents to achieve uniform capsule filling.

A good flow ability of granules or powder ensures efficient mixing, uniform dose as well as weight distribution in solid dosage form.

Keeping in view the objective two main areas were identified to cater the main cause of problem that is flowability of granules, first is reformulation of product: use of excipients that would aid in manufacturing of large, uniform, spherical \& dense granules, second is redesign of manufacturing techniques. For this reason series of trials were conducted to select most appropriate excipients and their optimum ratios, subsequently evaluating and identifying parameters obtained from angle of repose, carr's index \& Hausner Ratio.

\section{Discussion}

The project selected to facilitate, improve the process of filling, reduction of variation in weight of capsules and reduce the number of workers utilization for the capsule manufacturing, which is based on herbal formulation in Herbion, we have been utilizing Manual Capsule Filling System which fills one batch of capsule with 15 operators in 40 hours. But with increased demand and new technology in hand which can not only speed up process but also save time, labor, energy and money by utilizing Automatic Capsule Filling Machine.

For Automatic Machine we needed to reformulate the products with respect to its physical attributes and process parameters and it is achieved by using high quality and more compatible raw materials and manufacturing process there for we got more robust formulation in order to achieve better flow which ultimately provided and ensured efficient mixing, uniform dose as well as weight distribution in solid dosage form.

Keeping in view the objective two main areas were identified to cater the main cause of problem that is flowability of granules,

Improvement of Formulation:

Redesign of Manufacturing Techniques

Use of excipients that would aid in manufacturing and process modification to get large, spherical in shape, uniform in size \& dense granules and for this reason series of trials conducted to select excipients and optimum ratio, subsequently the size \& shape of granules observed from microscope for uniformality evaluating the identifying parameters obtained from angle of repose, carr's index \& Hausner Ratio shows significant improvement.

\section{Acknowledgement}

I would never have been able to finish my dissertation without the guidance of my team members, help from friends, and support from my family.

I would like to express my deepest gratitude to my colleague, Mr. Kamran Alam, for his excellent guidance, caring, patience, and providing me with an excellent support for doing research project. I would like to thank Dr. Zeeshan Ahmed Shaikh, who showed confidence on me and let me experience the research, patiently supported my study. I would also like to thank Mr. Nadeem Khalid and Mr. Abid Mumtaz, for allowing my study, research and helping me to develop my background in Product Development and Process Improvement. 
I would like to thank Mr. Imranulla Shariff and Ms. Sidra Hussain who always willing to help and give his best suggestions and guidance. I also like to thank all the staff members and course facilitators of PIQC.

Many thanks to Ms Rabia Bashir, Mr. Ali-ul-Azim, Mr. Kamran Aleem, Mr. Samar Abbas, It would have been a lonely lab without their participation in manufacturing of trial batches and evaluations, and other co-workers of different departments for helping me, this research would not have been possible without their helps.

Finally, I would also like to thank my parents, my wife and my lovely daughter, brothers, sister and also like to thank Ms. Hina Rehman for support in my research and paper writing. They were always supporting me and encouraging me with their best wishes, cheering me up and stood by me through the good times and bad.

\section{References}

[1] Anthony J. Hlinak, Kamal Kuriyan, Kenneth R. Morris, Gintaras V. Reklaitis,Prabir K. Basu Journal of Pharmaceutical Innovation,1(1) 12-17

[2] Charu V. Navaneethan, Shahrzad Missaghi, and Reza Fassihi, AAPS PharmSciTech. 6(3): E398-E404

[3] Rakhi B. Shah, Mobin A. Tawakkul, and Mansoor A. Khan, AAPS PharmSciTech. 2008 March; 9(1): 250-258.

[4] AbdulMobeen Faqih, Bodhisattwa Chaudhuri, Fernando J. Muzzio, M. Silvina Tomassone, Albert Alexander, Steve Hammond, Volume 52, Issue 12, pages 4124-4132, December 2006

[5] T. Dyakowski, S.P. Luke, K.L. Ostrowski, R.A. Williams, Volume 104, Issue 3, October 1999, Pages 287-295

[6] ASTM American Society for Testing and Materials Standards; C1444-00 Test Method for Measuring the Angle of Repose VOL $15.01,2005$

[7] Excipient General Chapters USP 29-NF24 page 3017, Pharmacopeial Forum : Volume No. 28(2) Page 618

[8] Carr RL. Evaluating Flow Properties of Solids. Chem. Eng. 1965;72:69-72

[9] Raymond C Rowe, Paul J Sheskey, Marian E Quinn. Handbook of Pharmaceutical Excipients - sixth edition 